\title{
Quantitation of intraepithelial lymphocytes in human jejunum
}

\author{
ANNE FERGUSON AND D. MURRAY \\ From the University Departments of Bacteriology and Immunology (Western Infirmary) and Pathology (Royal \\ Infirmary), Glasgow, Scotland
}

SUMMARY An estimate of the number of intraepithelial lymphocytes in jejunal villous epithelium can be obtained by differential counting of nuclei in the epithelium. From counts carried out in 160 jejunal biopsies from patients who did not have coeliac disease the normal range has been established as 6-40 intraepithelial lymphocytes per 100 villous epithelial cells. In some biopsies there was a moderate increase in the intraepithelial lymphocyte count; this was probably an objective measurement of 'increased chronic inflammatory cell infiltrate'.

Intraepithelial lymphocyte counts were high in untreated coeliac disease; counts were lower, but rarely within the normal range, in coeliac patients on a gluten-free diet. Counts were normal in most autoimmune diseases, ulcerative colitis, and Crohn's disease. There were abnormal intraepithelial lymphocyte counts in four patients, with otherwise normal jejunal histology, in whom no cause had been found to explain prolonged and incapacitating gastrointestinal symptoms.

In man, the layer of cells covering the small intestinal villi contains not only columnar epithelial cells and goblet cells, but also many lymphocytes and an occasional eosinophil or mast cell (Toner and Ferguson, 1971). The cells of the lamina propria include macrophages, plasma cells, lymphocytes, mast cells and eosinophils, and frequently lymphocytes can be observed in transit across the villous epithelial basement membrane.

When assessing intestinal biopsy histology, the pathologist often has the impression that there are increased numbers of inflammatory cells in the lamina propria, but this is difficult to quantitate. From work in animal tissues (Darlington and Rogers, 1966) it seems that the degree of lymphocyte infiltration in epithelium can be easily and reliably measured simply by a differential count of the nuclei in the epithelial cell layer. If this quantitation could be applied to human biopsy material it would provide at least one objective measurement of chronic inflammation in the jejunum.

To determine the feasibility of carrying out counts of villous intraepithelial lymphocytes we examined sections from 200 routinely obtained jejunal biopsies. We established the normal range of values for the degree of lymphocyte infiltration, and we were then able to determine whether the numbers of intraReceived for publication 17 September 1971. epithelial lymphocytes were increased or decreased in biopsies from patients with ulcerative colitis, Crohn's disease, coeliac disease, autoimmune diseases, and several other conditions.

\section{Materials and Methods}

\section{JEJUNAL BIOPSIES}

Biopsy specimens were obtained from the first loop of jejunum using a Crosby or Watson capsule and were fixed in formalin, examined with the dissecting microscope, then routinely embedded, sectioned at $7 \mu$ at three levels, and stained with haematoxylin and eosin. Two hundred biopsies were selected for histological reassessment; 160 were from patients who did not have clinical coeliac disease; dissecting microscopy had shown finger, tongue, or leaf-shaped villi, or short ridges (Booth, Stewart, Holmes, and Brackenbury, 1962; Stewart, Pollack, Hoffbrand, Mollin, and Booth, 1967). Twenty biopsies were from patients with adult coeliac disease taking a normal diet, and 20 were from patients with adult coeliac disease taking a gluten-free diet. The diagnosis of coeliac disease was based on (1) jejunal histology of subtotal villous atrophy or severe partial villous atrophy and (2) evidence of clinical, biochemical, and/or histological improvement when gluten was withdrawn from the diet. 
QUANTITATION OF INTRAEPITHELIAL LYMPHOCYTES

Differential counts of nuclei were carried out in the epithelium covering the villi. Counts were made in areas of the slide where the tissue was well orientated; the plane of the section passed vertically through the epithelium and the basement membrane was easily identified. The epithelium was examined using the highest power of the microscope and the nuclei of epithelial cells, goblet cells, and lymphocytes could be readily distinguished and counted (Fig. 1). When the section contained only part of a nucleus, this was included in the count if it could be firmly classified as epithelial or lymphocyte. Small, unclassifiable nuclear fragments were ignored. Lymphocyte nuclei were characteristically basally situated and they had dense nuclear staining. The nuclear shape was often very irregular and the surrounding lymphocyte cytoplasm was very pale. A single field usually contained 30-40 epithelial cells and a variable number of intraepithelial lymphocytes. Nuclei of goblet cells were not counted; intraepithelial eosinophils and lymphocytes in transit across the basal lamina were noted, but not included in the final calculation of the lymphocyte count. For each specimen, at least 500 cell nuclei (epithelial and lymphocyte) were counted. The result was expressed as the number of intraepithelial lymphocytes per 100 villous epithelial cells.

No difficulty was encountered in carrying out the differential counts as long as care was taken to count areas of the slide where the plane of section was vertical to the epithelium.

\section{USE OF PROBABILITY CURVES TO ESTABLISH THE NORMAL RANGE}

Hoffmann (1963) described a simple method for the determination of the range of normal values for a clinical laboratory test. This is based on an analysis of the distribution of measurements in samples routinely submitted from hospital wards and clinics. From the results of intraepithelial counts in the 160 noncoeliac biopsies a probability curve was constructed, and the range of 'normal values' obtained.

The intraepithelial lymphocyte counts were arranged in groups with counts of $<4 ; 4 \cdot 1-8 ; 8 \cdot 1-12 \ldots$ $>100$. From the number of biopsies in each group a cumulative percentage of biopsies for each lymphocyte count value can be calculated. The cumulative percentage is plotted against the group values for intraepithelial lymphocyte count on probability graph paper. Hoffmann has shown that, if a straight line can be drawn through the central points, this line corresponds to a normally distributed series of values and is likely to represent the range of values in a healthy population; the distortions at the upper and lower ends of the probability curve are due to the presence, in a series of samples from hospital patients, of pathologically high and pathologically low values. The range of normal



Fig. 1 Human jejunal villous epithelium; the nuclei of lymphocytes can readily be distinguished from those of epithelial cells. Haematoxylin and eosin $\times 780$. 
values can be obtained by noting where the straight line intersects the $5 \%$ and $95 \%$ lines of the probability paper.

NORMAL RANGE BASED ON INTRAEPITHELIAL LYMPHOCYTE COUNTS IN CONTROL PATIENTS Within the group of 160 non-coeliac biopsies there were specimens from 40 patients (21 male, 19 female) in whom biopsy had been carried out for clinical reasons but in whom, in the final analysis, there was no evidence of inflammatory bowel disease or immunological abnormality. The ages of these patients ranged from 11 to 76 years. Clinical diagnoses are listed in Table I. The mean and standard deviation (SD) of the intraepithelial lymphocyte counts in these 40 patients were calculated. The 'normal range' was taken as mean value \pm 2 SD.

\begin{tabular}{ll}
\hline Diagnosis & Number of Patients \\
\hline Relatives of patients with disaccharidase & 7 \\
$\quad$ deficiency & 3 \\
Primary adult disaccharidase deficiency & 2 \\
Paget's disease & 3 \\
Idiopathic hypercalcuria & 1 \\
Diabetes mellitus & 4 \\
Schizophrenia (to have trial of gluten withdrawal) & 3 \\
Haemochromatosis & 3 \\
Small stature & 8 \\
Nutritional vitamin or iron deficiency (after therapy) & 1 \\
Orthostatic proteinuria & \\
Investigation for possible mesenteric ischaemia & 5 \\
(No small bowel disease found) & $\mathbf{3}$ \\
\hline
\end{tabular}

Table I Final diagnoses in 40 patients used to establish a normal range of intraepithelial lymphocyte counts in jejunal biopsies

After the normal range had been established the results of the intraepithelial lymphocyte counts in the 200 biopsies were re-examined, first, to find if any disease was associated with high or low lymphocyte count, and, secondly, to review diagnoses of the patients with exceptionally high or low counts.

\section{Results}

The range of villous intraepithelial lymphocyte counts in 160 biopsies from non-coeliac patients is shown in Figure 2. Figure 3 shows the counts in the 40 selected 'control' biopsies and in the 40 biopsies from patients with coeliac disease.

NORMAL RANGE FROM PROBABILITY CURVE The curve of intraepithelial lymphocyte counts in the 160 non-coeliac biopsies, plotted against cumulative percentage, is shown in Figure 4. A straight line can be drawn through the four central points, as shown. This intersects the $5 \%$ and $95 \%$ lines on the probability paper at points correspond-

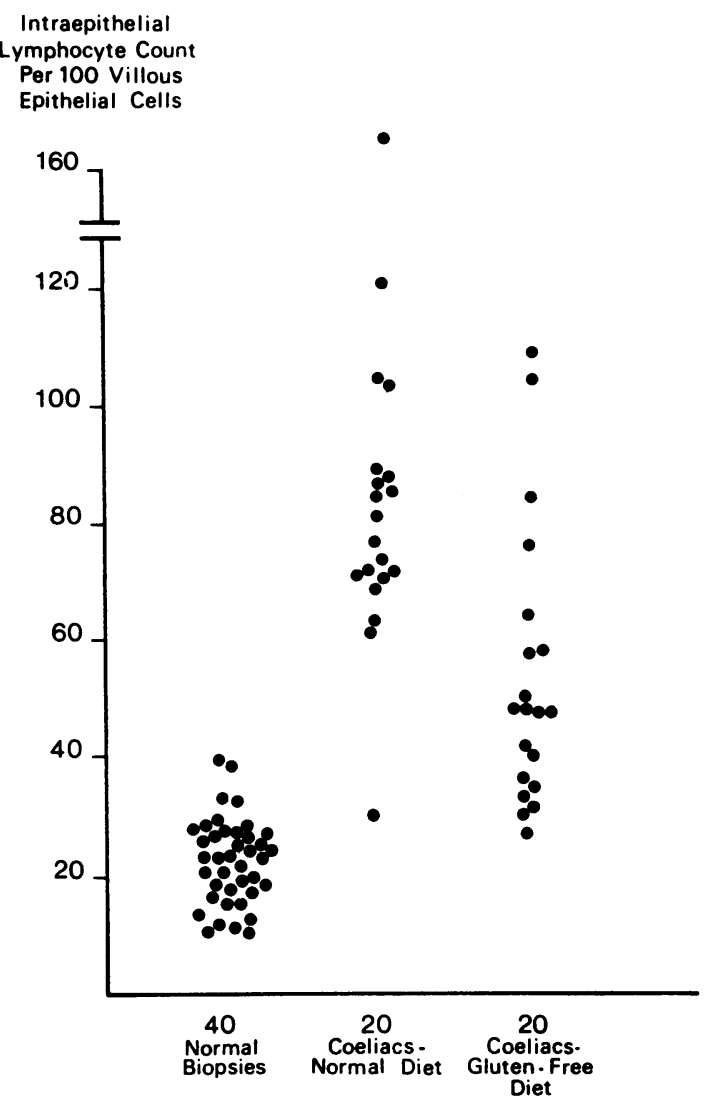

Fig. 2 Distribution of intraepithelial lymphocyte counts in 160 jejunal biopsies from patients who did not have coeliac disease. Results expressed as number of intraepithelial lymphocytes per 100 villous epithelial cells.

ing to intraepithelial lymphocyte counts of 7 and $\mathbf{4 0 .}$ Thus, from analysis of the results of intraepithelial lymphocyte counts in 160 jejunal biopsies from noncoeliac patients the range of 'normal values' has been established as 7 to $\mathbf{4 0}$ intraepithelial lymphocytes per 100 epithelial cells.

NORMAL RANGE BASED ON 'NORMAL' BIOPSIES As shown in Fig. 3 the range of intraepithelial lymphocyte counts in $\mathbf{4 0}$ biopsies from presumed normal persons was 9.6-39.3 per 100 villous epithelial cells, with a mean value of $21 \cdot 1$ and SD $7 \cdot 5$. Taking the normal range as the mean \pm 2 SD this gives a range of $6 \cdot 1-36 \cdot 1$ intraepithelial lymphocytes per 100 villous epithelial cells.

These two methods give closely comparable values for a normal range: $7-40$ and $6 \cdot 1-36 \cdot 1$. We have, therefore, combined the results to give a normal range 
NUMBER OF BIOPSIES



Fig. 3 Intraepithelial lymphocyte counts in jejunal biopsies from 40 immunologically normal patients; 20 adult coeliac patients taking a giuten-containing diet; and 20 adult coeliac patients taking a gluten-free diet. Results are expressed as number of intracpithelial lymphocytes per 100 villous epithelial cells.

INTRAEPITHELIAL LYMPHOCYTE COUNT PER 100 VILLOUS EPITHELIAL CELLS

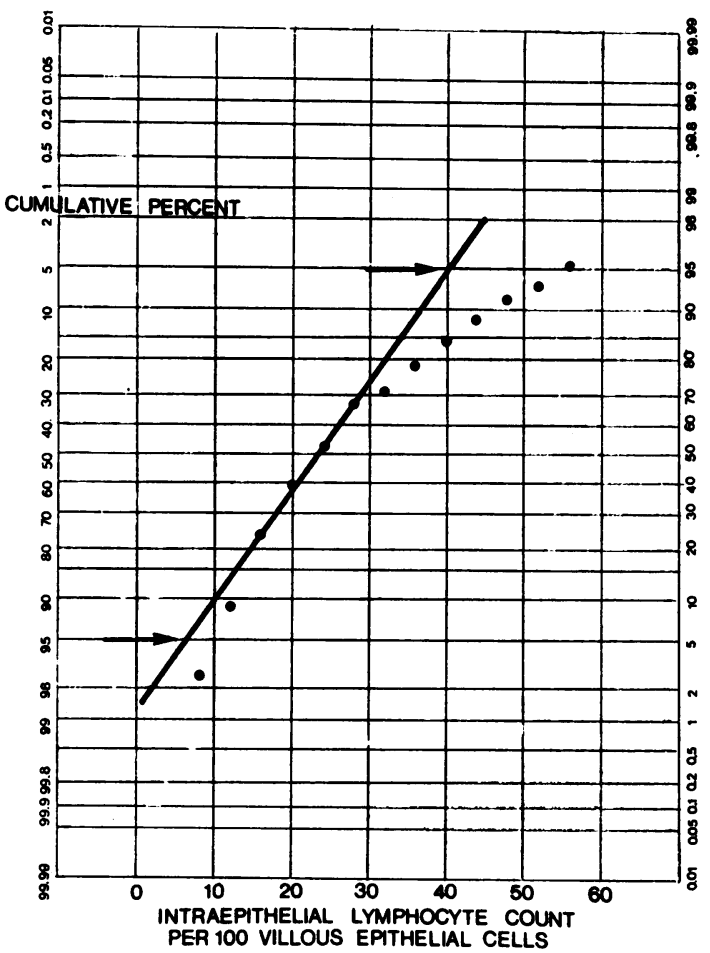

Fig. 4 Intraepithelial lymphocyte count plotted against cumulative percentage of 160 jejunal biopsies from patients who did not have coeliac disease.

of values for human jejunal intraepithelial lymphocyte counts as 6 to 40 intraepithelial lymphocytes per 100 villous epithelial cells.
INTRAEPITHELIAL LYMPHOCYTE COUNTS IN ADULT COELIAC DISEASE

Figure 3 shows the intraepithelial lymphocyte counts in jejunal biopsies from 20 untreated patients with adult coeliac disease and 20 coeliac patients taking a gluten-free diet. The duration of gluten withdrawal varied from six months to seven years. Intraepithelial lymphocyte counts in the untreated coeliac patients were significantly higher than in the controls $(P<0.001)$ and in only one of the 20 untreated patients was the count within the normal range. This could possibly be due to the fact that the patient had been very anorectic and had eaten little in the weeks before the diagnostic biopsy. Intraepithelial lymphocyte counts in coeliac patients taking a gluten-free diet were significantly lower than in untreated coeliac disease $(P<0.001)$ but were still higher than in the control patients $(P<$ 0.001 ). Only six of the post-treatment values were within the normal range. Of 11 patients studied before and after gluten withdrawal, the intraepithelial lymphocyte count fell after treatment in 10 , and the eleventh patient had had a normal pretreatment count.

The intraepithelial lymphocyte count bore no relation to the clinical state of the patient at the time of biopsy. In patients on a gluten-free diet, as well as a fall in the lymphocyte count there was an increase in cell height, villous height, reappearance of the brush border, and a fall in the numbers of inflammatory cells in the lamina propria. However, the effect of a gluten-free diet on lymphocyte count seemed to be relatively independent of the other manifestations of histological improvement: for example, the lymphocyte count was still high at 77 per 100 
epithelial cells in one post-treatment biopsy with almost normal leaf villi and tall columnar epithelial cells; in another patient the mucosal appearance remained almost flat, with severe partial villous atrophy and cuboidal epithelial cells, although the intraepithelial lymphocyte count had fallen to 37 from a pretreatment level of 104.

During the examination of specimens with the general morphology of partial villous atrophy, there was a noticeable variation in the degree of lymphocyte infiltration of the epithelium. More intraepithelial lymphocytes were present in the fields selected at the top of the villi, facing onto the intestinal lumen, than along the partially protected sides of the villi. In one specimen, there was enough material for formal counts at three levels of the mucosa. In the crypt epithelium there were $\mathbf{7 \cdot 2}$ lymphocytes per 100 epithelial cells; at the sides of the stunted villi the count was $32 \cdot 3$, and at the luminal surface $72 \cdot 3$. This luminopetal distribution of lymphocytes was not noticed in the jejunum of non-coeliac patients.

INTRAEPITHELIAL LYMPHOCYTE COUNTS IN OTHER GASTROINTESTINAL DISEASES

In Table II are listed the counts in biopsies from

\begin{tabular}{ll}
\hline Diagnosis & $\begin{array}{l}\text { Intraepithelial } \\
\text { Lymphocyte } \\
\text { Count }\end{array}$ \\
\hline Ulcerative colitis & $35 \cdot 2$ \\
& $32 \cdot 5$ \\
& $22 \cdot 5$ \\
Crohn's disease & $25 \cdot 8$ \\
& $40 \cdot 6$ \\
& $18 \cdot 1$ \\
& $24 \cdot 7$ \\
& $31 \cdot 8$ \\
& $34 \cdot 6$ \\
& $22 \cdot 2$ \\
Whipple's disease (in complete remission) & $18 \cdot 2$ \\
Colonic histiocytosis & $20 \cdot 8$ \\
& $32 \cdot 6$ \\
Gastrointestinal amyloidosis & $9 \cdot 7$ \\
Protein-losing enteropathy with lymphangiectasia & $28 \cdot 9$ \\
Round worm infestation & $21 \cdot 1$ \\
Giardiasis & $14 \cdot 0$ \\
Hypogammaglobulinaemia & $19 \cdot 2$ \\
\hline Tahle II & $13 \cdot 7$ \\
\end{tabular}

Table II Intraepithelial lymphocyte counts in jejunal biopsies from 21 patients with inflammatory or immunological diseases of the gastrointestinal tract

${ }^{1}$ Expressed as intraepithelial lymphocytes per 100 villous epithelial cells.

patients with ulcerative colitis, Crohn's disease, and several other gastrointestinal diseases. None of these disease states was accompanied by an increase or decrease in the intraepithelial lymphocyte count.
INTRAEPITHELIAL LYMPHOCYTE COUNTS IN AUTOIMMUNE DISEASES

These are listed in Table III. Only three of the 19 patients (one rheumatoid arthritis, one Hashimoto's thyroiditis, and the patient with lupus erythematosis, case 3 ) had counts above the normal range.

\begin{tabular}{lc}
\hline Diagnosis & $\begin{array}{c}\text { Intraepithelial } \\
\text { Lymphocyte } \\
\text { Count }^{1}\end{array}$ \\
\hline Pernicious anaemia & $7 \cdot 2$ \\
& $20 \cdot 8$ \\
& $20 \cdot 0$ \\
Rheumatoid arthritis & $33 \cdot 4$ \\
& $11 \cdot 3$ \\
Thyrotoxicosis & $45 \cdot 4$ \\
Hashimoto's thyroiditis & $21 \cdot 0$ \\
& $9 \cdot 4$ \\
& $25 \cdot 3$ \\
& $44 \cdot 0$ \\
& $15 \cdot 2$ \\
& $16 \cdot 9$ \\
& $7 \cdot 5$ \\
Idiopathic Addison's disease & $16 \cdot 9$ \\
Idiopathic thrombocytopenic purpura & $27 \cdot 6$ \\
Systemic lupus erythematosis & $13 \cdot 9$ \\
\end{tabular}

Table III Intraepithelial lymphocyte counts in jejunal biopsies from 19 patients with autoimmune diseases ${ }^{1}$ Expressed as intraepithelial lymphocytes per 100 villous epithelial cells.

PATIENTS WITH MODERATELY INCREASED NUMBERS OF INTRAEPITHELIAL LYMPHOCYTES The distribution of the 160 counts in non-coeliac patients (Fig. 2) shows that most fall within the normal range of 6 to 40 lymphocytes per 100 epithelial cells; within this range there is an approximately normal distribution. There is a secondary peak between 38 and 56; this is objective evidence that there is a moderate increase in the numbers of intraepithelial lymphocytes in some otherwise normal biopsies-a manifestation of the non-specific increase in numbers of intestinal chronic inflammatory cells in some patients.

PATIENTS WITH VERY HIGH INTRAEPITHELIAL LYMPHOCYTE COUNTS

Details of the seven non-coeliac patients with very high counts are given in Table IV. In case 1 the villi with increased lymphocyte count were overlying lymphoid nodules. Case 6 was the only one of three Indian or Pakistani patients in the series who had biopsy findings which would have been considered abnormal in a Caucasian. Dissecting microscopy showed a ridged mucosa; there were many chronic inflammatory cells in the lamina propria, and the epithelial cell height was reduced. However, these are normal findings in jejunal biopsies from Indians (Baker, Ignatius, Mathan, Vaish, and Chacko, 1962) 




Table IV Clinical details of seven patients with very high intraepithelial lymphocyte counts

'Expressed as intraepithelial lymphocyte count per 100 villous epithelial cells.

and it is not known why the small intestinal mucosa of healthy Indians appears so chronically inflamed. Cases 3 and 5 were suffering from well established immunological diseases, and presumably the increased numbers of gut lymphocytes were another manifestation of the immunological disturbances in erythema nodosum and disseminated lupus erythematosis. The finding of abnormal intraepithelial lymphocyte counts in patients 2,4 , and 7 is very interesting for no satisfactory diagnosis had been made in these patients despite the presence of very real and incapacitating symptoms-chronic diarrhoea, sore tongue, and abdominal pain. Certainly in case 7 it is likely that the increased number of gut lymphocytes was related to the underlying disease process, for spontaneous remission of symptoms (on no specific treatment) was accompanied by a fall in the intraepithelial lymphocyte count.

PATIENT WITH LOW INTRAEPITHELIAL LYMPHOCYTE COUNT

In one 57-year-old man the count was only $5 \cdot 8$ lymphocytes per 100 epithelial cells. This man had chronic glomerulonephritis of moderate severity and had been given a six-month course of azathioprine. While taking the drug he developed diarrhoea, which persisted after treatment had been stopped. Intestinal biopsy was carried out six months later and the histology had been considered to be normal. As all other investigations had proved negative a diagnosis of 'irritable bowel syndrome' had been made.

It seems likely that the azathioprine treatment was the cause of the depletion of intraepithelial lymphocytes and possibly also of the chronic diarrhoea.

\section{Discussion}

Quantitation of the villous intraepitheliallymphocytes can readily be carried out in routinely processed jejunal biopsy material. From analysis of counts in 160 jejunal biopsies from non-coeliac patients the range of normal values for the proximal jejunum, in man, is 6-40 intraepithelial lymphocytes per 100 villous epithelial cells.

Intraepithelial lymphocyte counts were normal in jejunal biopsies from patients with autoimmune diseases, ulcerative colitis, Crohn's disease, hypogammaglobulinaemia, and Whipple's disease. The low normal count in the patient with Whipple's disease is of interest since this man has an abnormality of peripheral blood lymphocytes; there is a poor in vitro blast response to phytohaemagglutinin (Maxwell, Ferguson, McKay, Imrie, and Watson, 1968) and the circulating lymphocytes have abnormally low contents of DNA and RNA (Glen, unpublished). Hourihane (1966) pointed out that increased numbers of lymphocytes may be seen 'within and between' the villous epithelial cells in untreated coeliac disease. We have confirmed this and also have found that the numbers of lymphocytes fall, but rarely to normal levels, after gluten withdrawal. However, it should be emphasized that electron microscope studies in man (Meader and Landers, 1967; Toner and Ferguson, 1971) have demonstrated that all the intraepithelial lymphocytes lie between, and not within, the epithelial cells.

In some cases of coeliac disease there was a characteristic distribution of the intraepithelial lymphocytes in the jejunum. Many more lymphocytes were present in the epithelial surface facing on to the gut lumen than in the short segments of epithelium along the sides of the villous projections. This would suggest that the increased numbers of intraepithelial lymphocytes are related to the presence of some antigens within the gut lumen rather than to antigens of the villous epithelial cells themselves; this being so, there are at least two possible explanations for the high numbers of lymphocytes in the epithelium in coeliac patients on a gluten-free diet. The patients may have been taking small, but still 
antigenic, amounts of gluten or they may have had gut lymphocytes sensitized to some other antigens, for example, the proteins of milk.

In four of eight patients with unequivocally abnormal intraepithelial lymphocyte counts (seven high, one low) no adequate explanation had been found for their symptoms, despite extensive gastroenterological investigation. One patient had a persistently sore tongue, one had severe abdominal pain, and two had chronic diarrhoea. The retrospective findings suggest that one application of this method for quantitating intraepithelial lymphocytes would be in the evaluation of jejunal biopsies from patients with unexplained gastrointestinal symptoms. If the lymphocyte count were abnormal appropriate investigations for immune deficiency, food allergy, or gut autoimmunity could be pursued.

The authors are grateful for the cooperation of Drs W. C. Watson, J. D. Maxwell, and E. Paton, who carried out many of the biopsy procedures and who had clinical care of the patients in this series.

\section{References}

Baker, S. J., Ignatius, M., Mathan, V. I., Vaish, S. K., and Chacko, C. C. (1962). Intestinal biopsy in tropical sprue. In Intestinal Biopsy (Ciba Foundation Study Group No. 14) edited by G. E. W. Wolstenholme and M. P. Cameron, pp. 84-101. Churchill, London.

Booth, C. C., Stewart, J. S., Holmes, R., and Brackenbury, W. (1962). Dissecting microscope appearances of intestinal mucosa. In Intestinal Biopsy (Ciba Foundation Study Group No. 14) edited by G. E. W. Wolstenholme and M. P. Cameron, pp. 2-23. Churchill, London.

Darlington, D., and Rogers, A. W. (1966). Epithelial lymphocytes in the small intestine of the mouse. J. Anat. (Lond.), 100, 813-830.

Hoffmann, R. G. (1963). Statistics in the practice of medicine. J. Amer. med. Ass., 185, 864-873.

Hourihane, D. O'B. (1966). The pathology of malabsorption states. In Recent Advances in Pathology, 8th ed., edited by C. V. Harrison, pp. 320-347. Churchill, London.

Maxwell, J. D., Ferguson, A., McKay, A. M., Imrie, R. C., and Watson, W. C. (1968). Lymphocytes in Whipple's disease. Lancet, 1, 887-889.

Meader, R. D., and Landers, D. F. (1967). Electron and light microscopic observations on relationships between lymphocytes and intestinal epithelium. Amer. J. Anat., 121, 763-774.

Stewart, J. S., Pollock, D. J., Hoffbrand, A. V., Mollin, D. L., and Booth, C. C. (1967). A study of proximal and distal intestinal structure and absorptive function in idiopathic steatorrhoea. Quart. J. Med., 36, 425-444.

Toner, P. G., and Ferguson, A. (1971). Intraepithelial cells in the human intestinal mucosa. J. ultrastruct. Res., 34, 329-344. 